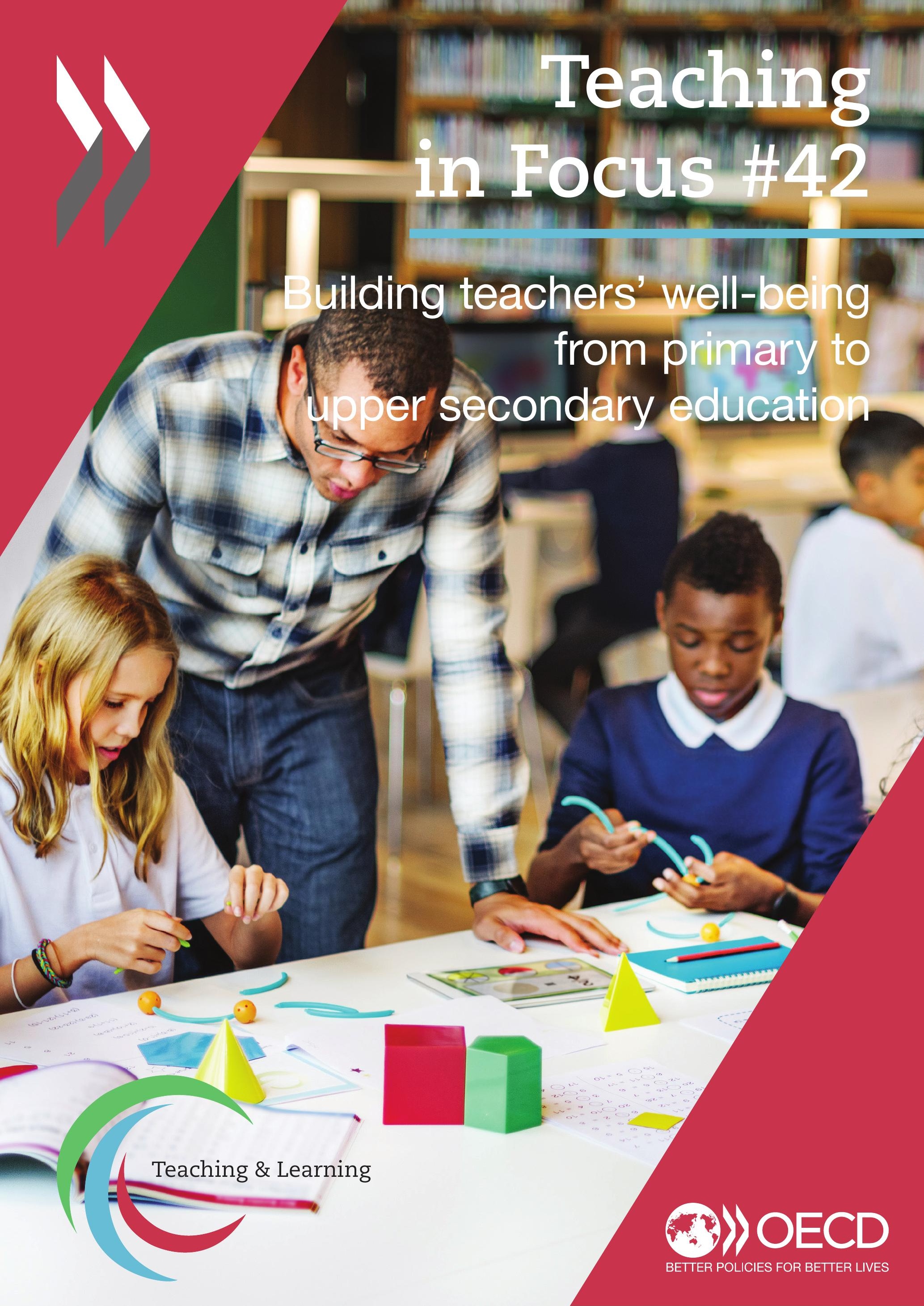




\section{Building teachers' well-being from primary to upper secondary education}

- An average of one out of six teachers in primary and secondary schools reported feeling "a lot" of stress in their work. Teachers who are stressed are more likely to want to leave the profession.

- Job satisfaction, school support, and motivation are strong factors in mitigating stress at work, as satisfied teachers tend to wish to remain in the profession despite high stress.

- School factors such as a supportive climate, collaboration and opportunities to participate in school decisions can enhance teachers' well-being and minimise the risks of attrition.

As education systems face a post-COVID-19 world, we must not lose sight of the importance of teachers' well-being. Already, prior to the pandemic, teachers were struggling to cope with workload and stress, as shown by the Teaching and Learning International Survey (TALIS), one of the first international efforts to capture the well-being of the teaching workforce. Nevertheless, schools and teachers have the tools to improve well-being and reduce stress at the work place.

The goal of this brief is to provide some glimpses into concrete actions that schools and education systems could take to improve teachers' well-being and job satisfaction.

\section{What is TALIS?}

The Teaching and Learning International Survey (TALIS), established in 2008, is the first major international survey of teachers and school leaders on different aspects affecting student learning. It gives voice to teachers and school leaders, allowing them to provide input into educational policy analysis and development in key areas.

The international target population for TALIS 2018 is lower secondary teachers and their school leaders in mainstream public and private schools. For the 2018 survey, a representative sample of 4000 teachers and their school principals from 200 schools were randomly selected in each country. Across all survey components, approximatively 260000 teachers responded to the survey, representing more than 8 million teachers in 48 participating countries and economies.

TALIS participants had the opportunity to opt for a survey implementation in upper secondary schools. Fifteen countries and economies decided to engage in a TALIS survey for primary education from which data is available for 12 and 11 countries and economies decided to engage in a TALIS survey for upper secondary education from which data is available for 10.

Data collection took place between September and December 2017 for Southern Hemisphere participants and March to May 2018 for Northern Hemisphere participants. Since the data were collected before the COVID-19 crisis, please note that some of the frequencies and relationships among the variables reported here may have changed. More information is available at www.oecd.org/education/talis.

\section{Schools and teachers can make a difference in reducing stress}

TALIS 2018 data collected from primary and secondary education prior to the pandemic show that around one out of six teachers reported feeling a lot of stress at school. An average of 17\% reported this in primary education in 13 countries and economies; 18\% in lower secondary education in 49 countries and economies; and 15\% in upper secondary education in 11 countries and economies.

These reported levels of teacher stress should not be dismissed. Regression analyses reveal patterns of attrition showing that teachers who report a great deal of stress in their work are more likely to report wanting to leave their work within the next five years in almost all countries and economies participating in TALIS in primary, lower secondary and upper secondary education. 
However, schools and teachers have the power to diminish the impact of stress on possible attrition. TALIS results for lower secondary education show that job satisfaction, school support, motivation, and self-efficacy give a somewhat different picture. The correlation with stress stops being significant in 18 countries and economies.

Figure 1. Relationship between teachers' experience of stress at work and task intensity

Likelihood of wanting to leave teaching within the next five years related to experiencing stress at work "a lot"

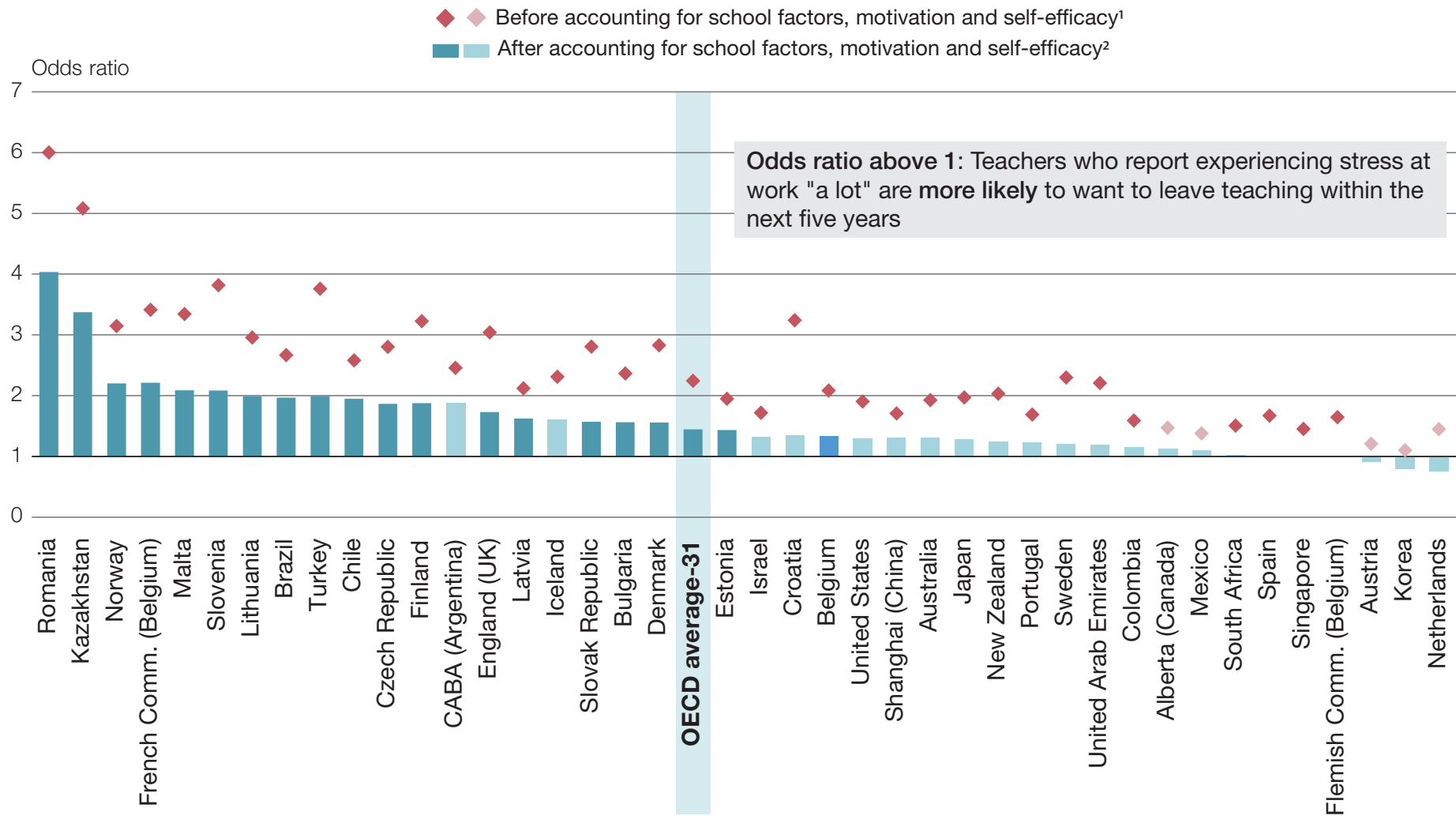

Notes: Statistically significant values are marked in a darker tone.

Results of binary logistic regression based on responses of lower secondary teachers.

An odds ratio indicates the degree to which an explanatory variable is associated with a categorical outcome variable. An odds ratio below one denotes a negative association; an odds ratio above one indicates a positive association; and an odds ratio of one means that there is no association.

The predictor is a dummy variable: the reference category refers to lower secondary teachers experiencing stress at work "quite a bit", "to some extent", "not at all".

The analysis is restricted to teachers reporting that their teaching in the target class is not directed entirely or mainly at special needs students. These data are reported by teachers and refer to a randomly chosen class they currently teach from their weekly timetable.

1. Controlling for gender, age, years of experience working at the school, working full-time and classroom composition of the target class (i.e. share of low achiever students, share of students with behavioural problems, share of students from socio-economically disadvantaged homes).

2. Controlling for gender, age, years of experience working at the school, working full-time and classroom composition of the target class and satisfaction with target class autonomy, effective professional development, participation in formal induction activities at current school, professional collaboration in lessons among teachers, teachers' views of how society values their profession, self-efficacy and job-satisfaction.

Countries and economies are ranked in descending order of the likelihood of wanting to leave teaching within the next five years related to experiencing stress at work "a lot". Source: OECD (2019), TALIS 2018 Results Nolume II): Teachers and School Leaders as Valued Professionals, TALIS, OECD Publishing, Paris, https://doi.org/10.1787/1d0bc92a-en, Tables II.2.68 and II.2.69.

The single biggest explanation for this difference in significance seems to be the introduction of the job satisfaction scale. In fact, there is a significant negative correlation between teachers' intent to leave the profession in the following five years and level of job satisfaction in 42 TALIS countries and economies. Additionally, the variables relating to school support, motivation, and self-efficacy appear to be closely related to job satisfaction itself. This suggests that, overall among TALIS countries but especially among the 18 countries for which stress stopped being significantly correlated, job satisfaction is a major factor in predicting the risk of teachers leaving teaching, sometimes regardless of level of stress.

The above indicates that both stress and job satisfaction play key roles in determining teacher attrition, with some differences between TALIS countries and economies. Stress reduction is a task that needs to be taken seriously by policy makers and school leaders. The importance of job satisfaction, however, suggests that it is possible to mitigate the negative effects of stress, thereby limiting teacher attrition. 


\section{Improving school climate to retain teachers}

What concrete actions can schools take to improve teachers' well-being? TALIS analysis shows that teachers who reported working in a collaborative school culture characterised by mutual support were more likely to report higher levels of well-being. Frequent collaborative actions among colleagues also reinforce positive relationships, strengthen trust, and support and enhance overall school climate. These are vital to improving teachers' well-being.

In primary education, TALIS shows that teachers who reported working in a collaborative and mutually supportive school culture are less likely to want to leave teaching in the next five years. Teachers in upper secondary education who have the opportunity to participate in school decisions are also less likely to want to leave the teaching profession (Figure 2).

These results suggest that schools that support measures to alleviate stress at the school, district and national level will improve the well-being of teaching professionals. Teachers will benefit from having additional help for their tasks and a space where their needs and difficulties are heard. Collaboration and school support are crucial to building the resilience of teachers and preparing them for change.

Figure 2. Relationship between the intention to leave the profession and the school's collaborative culture Increased likelihood of having the intention to leave teaching within the next five years

Panel A: Association with a collaborative school culture characterised

1.2

1.1

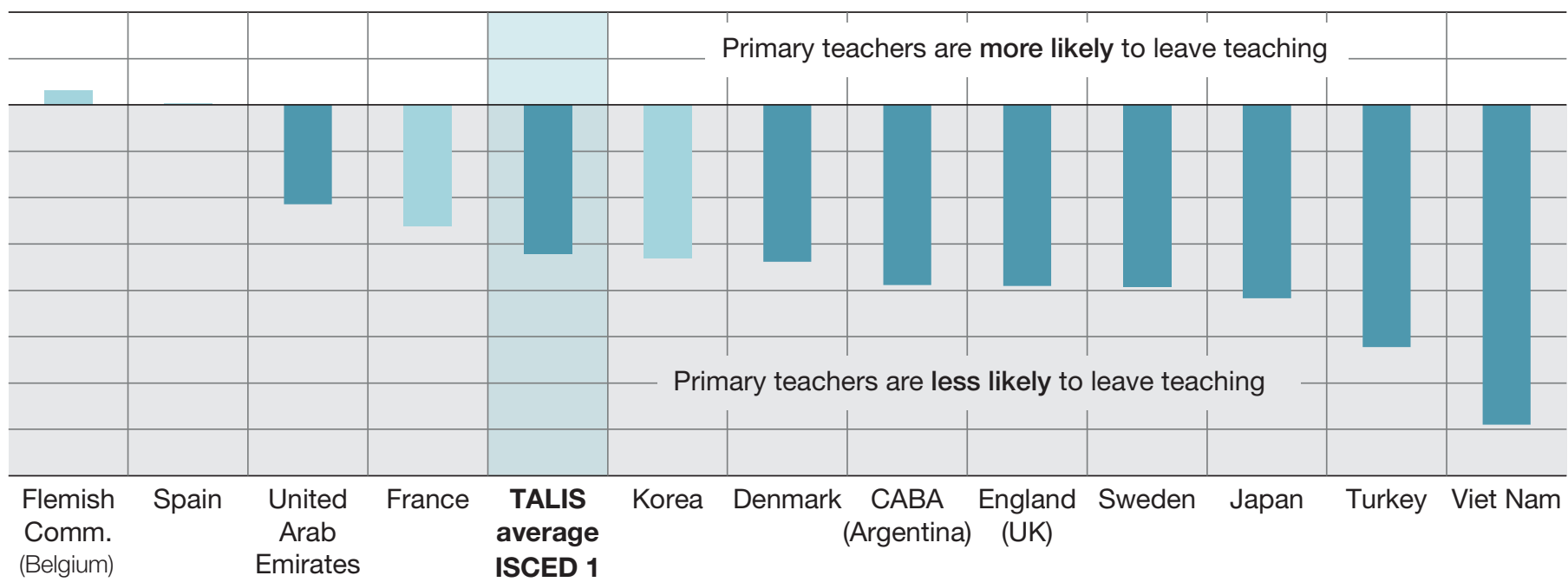

Panel B: Association with the school providing staff with opportunities to participate in school decisions in upper secondary education

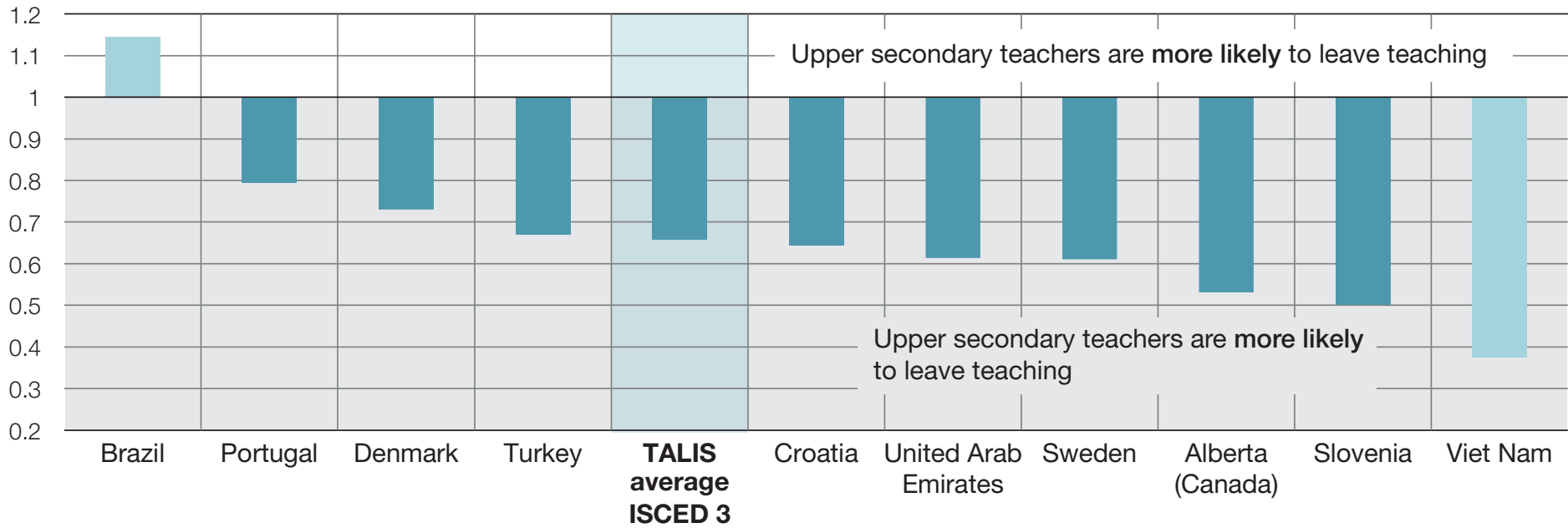

Note: Statistically significant values are marked in a darker tone.

Countries and economies are ranked in descending order of the likelihood of teachers intending to leave teaching within the next five years when there is a collaborative school culture that is characterised by mutual support in primary education (Panel A) and when the school provides staff with opportunities to participate in school decisions in upper secondary education (Panel B).

Source: OECD (2021), Teachers Getting the Best out of Their Students: From Primary to Upper Secondary Education, TALIS, OECD Publishing, Paris, https://doi.org/10.1787/5bc5cd4e-en, Tables 6.37 and Table 6.38. 


\section{The bottom line}

Supporting and improving the well-being of teachers should be a crucial consideration for education systems as schools find their footing in a post-COVID-19 world. With the onset of the pandemic, teachers have faced even more challenges. They have had to adapt to virtual learning environments. In addition to their traditional responsibilities, they have had to prepare lessons for remote learning, and engage and assess students' learning from a distance. It is not surprising if these novel working arrangements have further exacerbated the likelihood of teacher flight.

TALIS 2018 data prior to the pandemic show that the greater the stress teaching professionals feel, the greater the likelihood they will leave the profession. But they also indicate that stress-related attrition can be mitigated by increasing job satisfaction.

As findings show that school characteristics help teachers cope with their challenges, school-level policies have a role to play in developing resilience. This speaks to the need for school leaders to actively promote a school climate and working conditions that are more conducive to professional ways of working in schools. Government authorities could also place greater emphasis on collective rather than individual responsibility, giving the profession more responsibility and autonomy in ensuring high standards for their own work. Policy makers and school leaders can create the spaces and resources to promote collaborative practices but collaboration also relies on teachers' efforts and willingness to mobilise their knowledge, and trust and support each other to achieve long-term well-being. 


\section{Contact}

Pablo Fraser (pablo.fraser@oecd.org)1 and talis@oecd.org

\section{Note}

1. We would like to acknowledge the contribution to the preparation of this Teaching in Focus brief of Aakriti Kalra, formerly an external consultant, and Asuka Ohagi, OECD Analyst.

\section{For more information}

OECD (2020), TALIS 2018 Results (Volume II): Teachers and School Leaders as Valued Professionals, TALIS, OECD Publishing, Paris, https://doi.org/10.1787/19cf08df-en.

OECD (2021), Teachers Getting the Best out of Their Students: From Primary to Upper Secondary Education, TALIS, OECD Publishing, Paris, https://doi.org/10.1787/5bc5cd4e-en.

This paper is published under the responsibility of the Secretary-General of the OECD. The opinions expressed and the arguments employed herein do not necessarily reflect the official views of OECD member countries.

This document, as well as any data and map included herein, are without prejudice to the status of or sovereignty over any territory, to the delimitation of international frontiers and boundaries and to the name of any territory, city or area.

The statistical data for Israel are supplied by and under the responsibility of the relevant Israeli authorities. The use of such data by the OECD is without prejudice to the status of the Golan Heights, East Jerusalem and Israeli settlements in the West Bank under the terms of international law.

You can copy, download or print OECD content for your own use, and you can include excerpts from OECD publications, databases and multimedia products in your own documents, presentations, blogs, websites and teaching materials, provided that suitable acknowledgment of OECD as source and copyright owner is given. All requests for commercial use and translation rights should be submitted to rights@oecd.org.

Photo credits: Cover (c) Rawpixel; back page (c) Rawpixel, (c) wavebreakmedia, (c) Rawpixel

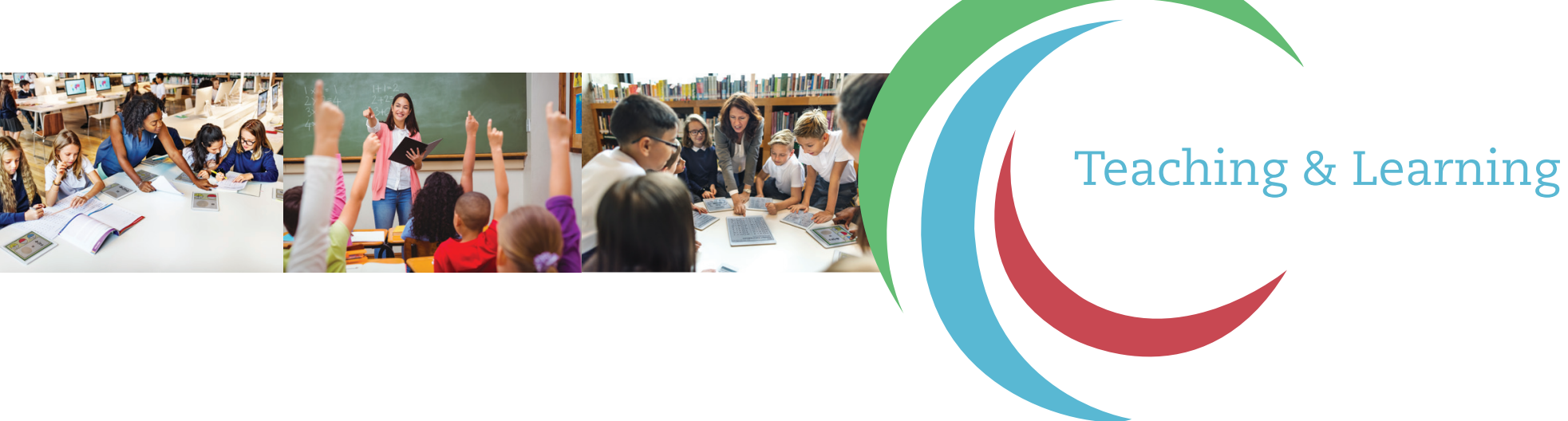

